\title{
Análise dos objetos de estudo da Comunicação Organizacional e das Relações Públicas
}

\author{
Analysis of the subject matters of Organizational \\ Communication and Public Relations
}

\section{Análisis de los objetos de estudio de la Comunicación Organizacional y de las Relaciones Públicas}

\section{Adriana Machado Casali}

- ABD em Comunicação Organizacional na Université de Montréal (Canadá)

- Doutora em Engenharia da Produção pela Universidade Federal de Santa Catarina (UFSC)

- Mestre em Administração, com concentração em Estratégias e Organizações, pela Universidade Federal do Paraná (UFPR)

- Especialista em Marketing Empresarial pela UFPR

- Bacharel em Relações Públicas pela UFPR e em Administração pela Fundação de Estudos Sociais do Paraná (Fesp)

- Professora adjunta do Departamento de Comunicação Social e do Programa de Mestrado em Administração da UFPR

- Pesquisadora do Grupo de Estudos sobre Comunicação Organizacional: Estratégias e Processos (Ecoep/UFPR)

- Autora de diversos capítulos de livros e artigos em periódicos em periódicos científicos nacionais e internacionais

- Autora de diversos trabalhos apresentados em congressos nacionais e internacionais

- amcasali@ufpr.br 
Uma diferença básica entre Comunicação Organizacional e Relações Públicas é o objeto de estudo de cada uma dessas disciplinas. Enquanto as Relações Públicas focam a relação organização/público, a Comunicação Organizacional trata da relação comunicação/ organização. A reflexão apresentada neste texto concentra-se em como estas relações conceituais são analisadas. Para ilustrar tal diferença é apresentado um exemplo de como uma mesma situação inspiraria pesquisas distintas nessas duas áreas de conhecimento.

PALAVRAS-CHAVE: COMUNICAÇÃO ORGANIZACIONAL • RELAÇÕES PÚBLICAS • OBJETOS DE ESTUDO

Abstract

One of the fundamental differences between Organizational Communication and Public Relations is the subject-matter studied in each of these fields. While Public Relations focuses on the organization/public relationship, Organizational Communication deals with the communication/organization relation. This text briefly examines how these conceptual relationships are analyzed and illustrates the distinctiveness of each field through an example of how a single situation could inspire the formulation of different research questions in Public Relations on the one hand, and Organizational Communication on the other.

KEYWORDS: ORGANIZATIONAL COMMUNICATION • PUBLIC RELATIONS • SUBJECT-MATTERS STUDIED

Resumen

Una diferencia básica entre la Comunicación Organizacional y las Relaciones Públicas es el objeto de estudio de cada una de estas disciplinas. Mientras que las Relaciones Públicas se centran en la relación organización/público, la Comunicación Organizacional trata de la relación comunicación/organización. La reflexión presentada en este texto se centra en cómo se analizan estas relaciones conceptuales. Para ilustrar tal diferencia se presenta un ejemplo de cómo una misma situación inspiraría investigaciones distintas en estas dos áreas del conocimiento.

PALABRAS CLAVE: COMUNICACIÓN ORGANIZACIONAL・RELACIONES PÚBLICAS • OBJETOS DE ESTUDIO 
$\mathrm{N}$ este breve ensaio discute-se uma diferença básica entre Comunicação Organizacional e Relações Públicas: o objeto de estudo de cada uma dessas disciplinas. Obviamente, essas áreas do conhecimento não se definem exclusivamente por essa característica, mas acredita-se que tal discussão possa elucidar alguns questionamentos sobre as fronteiras conceituais entre Relações Públicas e Comunicação Organizacional.

Os objetos de estudo da Comunicação Organizacional e das Relações Públicas, distinguem-se quando são consideradas as relações conceituais exploradas por esses domínios de pesquisa. Enquanto as Relações Públicas focam a relação organização/público, a Comunicação Organizacional trata da relação comunicação/organização. A especificidade desses focos de interesse se deve, em parte, ao fato de que essas áreas de conhecimento são originárias de diferentes disciplinas. Como consequência de seus interesses distintos, um mesmo episódio organizacional pode inspirar perguntas de pesquisa distintas em cada área.

Neste texto limitamo-nos a refletir sobre o objeto de estudo de cada uma dessas disciplinas, ciente de que a reflexão conceitual sobre essas áreas não está circunscrita a esta questão específica. É importante observar que além da diferença aqui destacada, a Comunicação Organizacional e as Relações Públicas se distinguem por outros aspectos significativos, mas também apresentam pontos de convergência.

\section{Objetos de estudo}

Os objetos de estudo da Comunicação Organizacional e das Relações Públicas se diferenciam quando são consideradas as relações conceituais estabelecidas nessas disciplinas.

Grunig e Hunt (1984, p. 6) definem as Relações Públicas como "a administração da comunicação entre uma organização e seus públicos”. Dessa definição decorre a noção de que o objeto de estudo das Relações Públicas é a relação organização/público (KUNSCH, 1997). Assim sendo, os estudos em Relações Públicas, que se desenvolveram sob a égide da comunicação de massa (ZORN, 2002), dentre outras preocupações, se concentram em compreender como a opinião pública percebe determinada organização ou como os assuntos públicos afetam a atuação desta. Nesse sentido, os estudos em Relações Públicas observam as propriedades e os efeitos das mídias, além de dedicarem considerável atenção aos meios de comunicação ou à adequação de uma mídia para determinadas audiências (ou públicos).

Os estudos em Comunicação Organizacional, derivados sobretudo dos estudos em Psicologia Social e da disciplina Speech Communication (TOMPKINS, WANCA-THIBAULT, 2001; ZORN, 2002), têm como questão de fundo a compreensão de: como a comunicação possibilita aos indivíduos organizar a vida 
em sociedade; como as pessoas trabalham juntas; como são criadas, mantidas e transformadas as estruturas sociais em geral e as organizações em particular. Assim sendo, essa disciplina preocupa-se em compreender a comunicação organizacional um processo de construção de significados compartilhados que possibilita o desenvolvimento de atividades coordenadas para a realização de objetivos comuns a um determinado grupo social. Como resume DeWine (2001, p. 5), "comunicação organizacional é uma disciplina que procura ajudar os indivíduos a compreender a natureza central da comunicação em todos os aspectos do trabalho organizacional”.

A Comunicação Organizacional, muito mais do que considerar a comunicação de massa ou a comunicação pública, foca sua atenção na forma pela qual os indivíduos se organizam para a realização de um trabalho coletivo e por isso observa a comunicação nos níveis intrapessoal, interpessoal, em pequenos grupos e em multigrupos (KREPS, 1990; EISENBERG, GOODALL JR., 2001). Como cada um desses níveis influencia os demais e como esses níveis de comunicação interagem na constituição de uma organização, todos são igualmente importantes para compreender a complexidade da comunicação humana e por consequência da Comunicação Organizacional.

De acordo com Smith (1993), as pesquisas em Comunicação Organizacional diferenciam-se segundo o modo pelo qual se percebe a relação comunicação / organização. Entende-se, assim, que o objeto de estudo da Comunicação Organizacional se refere a essa relação. Miller (2003) reforça essa noção quando explica que o objetivo da Comunicação Organizacional é compreender como o contexto organizacional influencia os processos de comunicação e como a natureza simbólica da comunicação diferencia o contexto organizacional. Segundo Miller (2003), a Comunicação Organizacional é uma disciplina eclética na qual se observam uma grande variedade de abordagens teóricas que consideram a interseção dos processos de comunicação e organização.

Para Smith (1993) existem três relacionamentos possíveis entre organizações e comunicação: de contêiner, de produção e de equivalência. Na relação de contêiner, percebe-se a comunicação como algo que ocorre "nas" organizações, ou seja a comunicação é uma variável organizacional passível de ser administrada. Nas relações de produção e de equivalência, entende-se a comunicação "como" organização, ou seja, a comunicação pode ser entendida como metáfora para compreender a organização ${ }^{1}$. Assim, na relação de produção, não apenas a comunicação implica alguma forma de organização, como o contrário também é válido. Na relação de equivalência, organização é comunicação e vice-versa. Logo, percebe-se que entender a comunicação "como" organização é uma perspectiva muito mais ampla do que a noção anterior, na qual a comunicação é vista como algo que a organização possui. Essas diferentes percep-

1 Para uma reflexão um pouco mais aprofundada sobre a percepção da comunicação enquanto metáfora ou variável organizacional cf. Casali (2008). 
ções da relação comunicação/organização talvez sejam a causa do transtorno dissociativo observado na disciplina, pois, segundo Taylor et al. (no prelo), a Comunicação Organizacional sofre do distúrbio de personalidade múltipla.

Quando a comunicação é considerada como variável organizacional, é possível identificar diversas convergências e similaridades entre Comunicação Organizacional e Relações Públicas. Nesse sentido, a função das Relações Públicas é "administrar" a comunicação que ocorre "nas" organizações (ou pelo menos uma boa parte dela).

Segundo a visão da comunicação "como" organização, a comunicação é um fenômeno natural cujas propriedades intrínsecas possibilitam a atividade grupal coordenada, isto é, a organização social. Desse ponto de vista, as Relações Públicas se diferenciam da Comunicação Organizacional, pois esta considera a comunicação como única forma pela qual os indivíduos interagem e assim são capazes de agir coletivamente. Assim sendo, ao contrário das Relações Públicas, não existe um profissional de comunicação organizacional, pois, afinal, todos os indivíduos em uma organização comunicam e, ao se comunicarem, se organizam.

Para ilustrar de modo bastante simplificado a diferença entre os focos de análise da Comunicação Organizacional e das Relações Públicas, considere-se uma situação na qual uma empresa toma uma decisão específica (construir uma nova unidade ou demitir mil funcionários, pouco importa o escopo ou a natureza do impacto da decisão). Em tal circunstância, algumas possibilidades de análise da Comunicação Organizacional seriam: compreender os processos de comunicação que atribuíram ao ambiente organizacional o sentido de necessidade de uma decisão específica; analisar a constituição comunicacional da decisão tomada; verificar como diversas posições e ações individuais convergem para e se traduzem em uma decisão coletiva; observar os discursos e as instâncias dialógicas presentes (e/ou ausentes) no processo de tomada de decisão; compreender como essa decisão "faz sentido" no contexto organizacional; etc. Nesse mesmo cenário, uma investigação a partir das Relações Públicas, dentre outras alternativas, poderia se preocupar com: o papel da assessoria de Relações Públicas para garantir que o ponto de vista de cada um dos públicos afetados pela decisão estivesse representado no processo decisório; o modo como a decisão será informada para os públicos de interesse; os canais e meios de comunicação mais indicados para a veiculação de tal informação; a linguagem mais adequada para comunicar a mensagem a cada público de interesse; os impactos dessa informação sobre a opinião pública e a imagem da empresa; as percepções de cada público sobre a decisão tomada; etc.

\section{Considerações finais}

Embora existam diversos aspectos de convergência e divergência entre Comunicação Organizacional e Relações Públicas, neste texto se explorou uma dife- 
rença básica: o objeto de estudo de cada disciplina. As relações conceituais estudadas por essas áreas são distintas visto que as Relações Públicas investigam a relação organização/público, enquanto que a Comunicação Organizacional se preocupa em compreender a relação comunicação/organização.

Em decorrência desses diferentes objetos de estudo, observa-se que os estudos em Comunicação Organizacional e em Relações Públicas também se distinguem pelo modo como compreendem a organização. Por se preocuparem com a relação organização/público, os estudos em Relações Públicas investigam, sobretudo, as características das organizações nas quais suas técnicas são empregadas. Por sua vez, a Comunicação Organizacional - visto que se preocupa com a relação comunicação/organização - estuda o fenômeno organizacional em si e por vezes questiona o status ontológico das organizações ao procurar realizar uma análise das organizações da ótica da comunicação. Contudo, não cabe neste pequeno ensaio explorar como a Comunicação Organizacional e as Relações Públicas percebem as organizações, pois este poderia ser apontado como um outro diferencial entre essas duas disciplinas. Esta observação final é apresentada com o objetivo de ilustrar como, ao se considerar o objeto de estudo de cada uma dessas áreas de conhecimento, é possível identificar e analisar outros aspectos que distinguem e/ou aproximam a Comunicação Organizacional das Relações Públicas.

\section{Referências}

CASALI, Adriana Machado. Comunicação organizacional: a comunicação como variável e metáfora organizacional. In: JESUS, Eduardo de; SALOMÃO, Mozahir (Org.). Interações plurais: a comunicação e o contemporâneo. São Paulo: Editora Annablume, 2008. p.125-142.

DEWINE, Sue. The consultant's craft: improving organizational communication. New York: St. Martin's Press, 1994. 396 p. GRUNIG, James E.; HUNT, Todd. Managing public relations. New York: Holt, Rinehart and Winston, 1984. 550 p.

KREPS, Gary L. Organizational communication: theory and practice. New York: Longman, 1990. 331 p.

KUNSCH, Margarida M. Krohling. Relações públicas e modernidade: novos paradigmas na comunicação organizacional. São Paulo: Summus, 1997. $156 \mathrm{p}$.

MILLER, Katherine. Organizational communication: approaches and processes. Belmont, CA: Wadsworth Thomsom, 2003.

SMITH, Ruth C. Images of organizational communication: root metaphors of the organization-communication relation. International Communication Association Annual Conference. Washington, DC, USA. May, 1993.

TAYLOR, James R. et al. Comunicação e organizações: o essencial. Lisboa: Angelus Novus, [no prelo].

TOMPKINS, Phillip K.; WANCA-THIBAULT, Maryanne. Organizational communication: Prelude and prospects. In: JABLIN, Frederic M.; PUTNAM, Linda L. (Ed.). The new handbook of organizational communication: advances in theory, research and methods. Thousand Oaks: Sage Publications, Inc, 2001. p.xvii-xxxi.

ZORN, Theodore E. Converging within divergence: Overcoming the disciplinary fragmentation in business communication, organizational communication, and public relations. Business Communication Quarterly, v. 65, n. 2, p. 44-53, 2002. 